\title{
Active Microbial Sulfur Disproportionation in the Mesoproterozoic
}

\author{
David T. Johnston, ${ }^{1 *_{\dagger}}$ Boswell A. Wing, ${ }^{1 *_{\dagger}}$ James Farquhar, ${ }^{1}$ \\ Alan J. Kaufman, ${ }^{1}$ Harald Strauss, ${ }^{2}$ Timothy W. Lyons, ${ }^{3}$ \\ Linda C. Kah, ${ }^{4}$ Donald E. Canfield ${ }^{5}$
}

\begin{abstract}
The environmental expression of sulfur compound disproportionation has been placed between 640 and 1050 million years ago (Ma) and linked to increases in atmospheric oxygen. These arguments have their basis in temporal changes in the magnitude of ${ }^{34} \mathrm{~S} /{ }^{32} \mathrm{~S}$ fractionations between sulfate and sulfide. Here, we present a Proterozoic seawater sulfate isotope record that includes the less abundant sulfur isotope ${ }^{33} \mathrm{~S}$. These measurements imply that sulfur compound disproportionation was an active part of the sulfur cycle by $1300 \mathrm{Ma}$ and that progressive Earth surface oxygenation may have characterized the Mesoproterozoic.
\end{abstract}

There is a strong link between the oxidation state of the Earth's surface environment and the microbial sulfur metabolisms that influence the sulfur cycle $(1-3)$. This link is revealed through sulfur isotope studies where different microbial metabolisms contributed to the final isotopic composition of sulfur species preserved in the geologic record (4-6). The relation between isotopic fractionation due to sulfate-reducing prokaryotes (SRP; $\mathrm{SO}_{4}{ }^{2-} \rightarrow \mathrm{H}_{2} \mathrm{~S}$ ) and seawater sulfate concentration has been the primary tool for interpreting the sulfur isotope record of Earth surface oxidation (7-11). For example, the isotopic record of sedimentary sulfides reveals that SRP may have dominated the global sulfur cycle until the Neoproterozoic. After this, greater ${ }^{34} \mathrm{~S} /{ }^{32} \mathrm{~S}$ fractionations cannot be explained by sulfate reduction alone (1), and they likely reflect the added contribution of sulfur compound-disproportionating prokaryotes ( $\mathrm{SDP} ; \mathrm{S}^{0} / \mathrm{SO}_{3}{ }^{2-} / \mathrm{S}_{2} \mathrm{O}_{3} \rightarrow \mathrm{SO}_{4}{ }^{2-}+$ $\mathrm{H}_{2} \mathrm{~S}$ ). Because sulfide oxidation is responsible for the intermediate sulfur compounds used by SDP (12-15), the widespread activity of SDP has been interpreted to indicate increased

${ }^{1}$ Department of Geology and Earth System Science Interdisciplinary Center, University of Maryland, College Park, MD 20742, USA. ${ }^{2}$ Geologisch-Paläontologisches Institut und Museum der Westfälischen Wilhelms, Universität Münster, Corrensstraße 24, D-48149 Münster, Germany. ${ }^{3}$ Department of Earth Science, University of California, Riverside, CA 92521, USA. ${ }^{4}$ Department of Earth and Planetary Sciences, University of Tennessee, Knoxville, TN 37996, USA. ${ }^{5}$ Nordic Center for Earth Evolution and Institute of Biology, Southern Denmark University, Campusvej 55, 5230 Odense M, Denmark.

*These authors contributed equally to this work. $\dagger$ To whom correspondence should be addressed. E-mail: dtj@geol.umd.edu (D.T.J.); wing@essic.umd. edu (B.A.W.) atmospheric oxygen content (1). New data, however, suggest that the isotopic fractionation between seawater sulfate and sulfide in the Neoproterozoic may have been smaller than previously estimated $(16,17)$. This raises the prospect that the $\delta^{34} \mathrm{~S}$ record may not uniquely reveal the activities of SDP during the Neoproterozoic.

Recent experiments illustrated that SRP and SDP produce resolvable ${ }^{33} \mathrm{~S} /{ }^{32} \mathrm{~S}$ fractionations for similar magnitudes of ${ }^{34} \mathrm{~S} /{ }^{32} \mathrm{~S}$ fractionations $(18,19)$. In those experiments, the compositions of sulfate associated with SDP were more ${ }^{33} \mathrm{~S}$ enriched than sulfate associated with SRP (20). The fractionations preserved in the sulfur isotope record reflect largely the combined influence of these two metabolisms (6). We propose that by considering both the fractionations associated with ${ }^{33} \mathrm{~S} /{ }^{32} \mathrm{~S}$ and ${ }^{34} \mathrm{~S} /{ }^{32} \mathrm{~S}$, as preserved in ancient marine sulfide and sulfate minerals, we can elucidate the role of SRP and SDP on the global sulfur cycle. Here, we combine a steady-state, open-system isotope massbalance model with data from sediments deposited between $\sim 2000$ and $\sim 500$ million years ago (Ma) to constrain how sulfur isotope signatures are transferred through a global sulfur cycle that includes SRP and SDP (fig. S1). The model tracks the sulfur isotopic composition of the seawater sulfate and reactive sulfide reservoirs as sulfur is microbially cycled between them. A fundamental assumption in the model is that any reoxidation flux from reactive sulfide to seawater sulfate ultimately occurs through disproportionation reactions.

A series of model calculations were run incorporating the whole range in ${ }^{33} \mathrm{~S} /{ }^{32} \mathrm{~S}$ and ${ }^{34} \mathrm{~S} /{ }^{32} \mathrm{~S}$ fractionations observed in pure and enriched culture experiments (21). Inputs to the model are (i) the experimentally calibrated ${ }^{33} \mathrm{~S} /{ }^{32} \mathrm{~S}$ and ${ }^{34} \mathrm{~S} /{ }^{32} \mathrm{~S}$ fractionations associated with SRP and SDP, (ii) the isotopic composition of the sulfate entering the model through the seawater sulfate reservoir (the origin in Figs. 1 to 3), (iii) the proportion of sulfate entering the model through the seawater sulfate reservoir that leaves the model as pyrite rather than as sulfate minerals $\left(f_{\mathrm{py}}\right)$, and (iv) the proportion of sulfur entering the reactive sulfide pool that is completely reoxidized to sulfate $\left(f_{\mathrm{r}-\mathrm{o}}\right)$. We began each calculation by choosing fractionations for SRP and SDP. By varying $f_{\mathrm{py}}$ and $f_{\mathrm{r}-\mathrm{o}}$, a unique array of relationships between the $\delta^{34} \mathrm{~S}$ and $\Delta^{33} \mathrm{~S}$ of model seawater sulfate $\left\{\Delta^{33} \mathrm{~S}=\delta^{33} \mathrm{~S}\right.$ $\left.\left[\left(\delta^{34} \mathrm{~S} / 1000+1\right)^{0.515}-1\right] \times 1000\right\}(22,23)$ was produced (fig. S2).

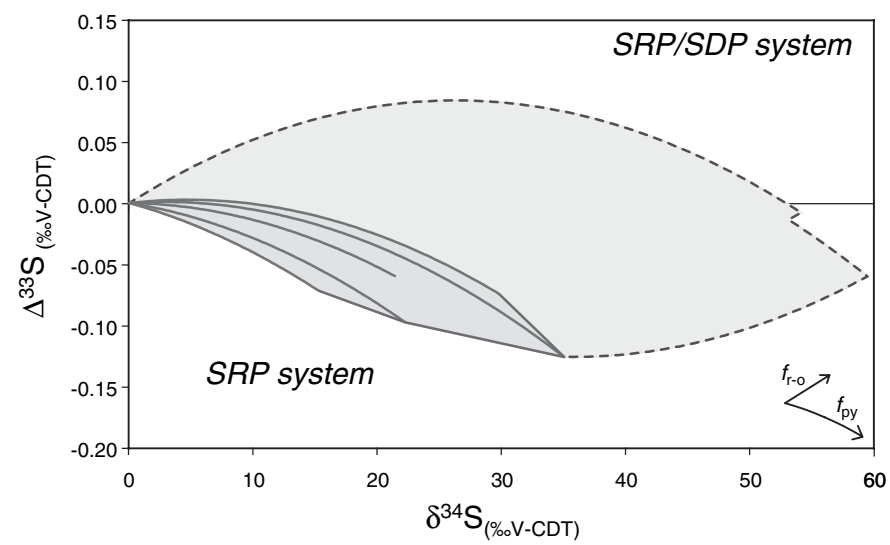

system). The field bound by a dashed line is accessible to a combined SRP-SDP microbial $S$ cycle (SRP/SDP system). (Inset) The direction that $\Delta^{33} S$ versus $\delta^{34} S$ trajectories evolve as $f_{\mathrm{py}}$ and $f_{\mathrm{r}-\mathrm{o}}$ increase. The different $\Delta^{33} S$ versus $\delta^{34} S$ regions accessed by the SRP and SRP/SDP systems are used to assess the microbial contribution to the oceanic sulfur cycle at the time of sulfate deposition. Modeled and measured isotopic compositions are standardized to the V-CDT (Vienna Canyon Diablo Troilite) scale. 


\section{R E P O R T S}

As $f_{\mathrm{py}}$ increases in a model system including only SRP, the composition of seawater sulfate becomes ${ }^{34} \mathrm{~S}$ enriched relative to the sulfate entering the model (Fig. 1) $(5,11,24-26)$. In this case, the $\Delta^{33} \mathrm{~S}$ values of model seawater sulfate become more negative as $\delta^{34} \mathrm{~S}$ values increase (18). This is reflected in the orientation of the curves that outline the field of $\Delta^{33} \mathrm{~S}$ and $\delta^{34} \mathrm{~S}$ in Fig. 1 labeled SRP system. When the model $\mathrm{S}$ cycle is expanded with a reoxidative subcycle that allows for microbial sulfur disproportionation, increasing $f_{\text {r-o }}$ leads to seawater sulfate that is more enriched in ${ }^{34} \mathrm{~S}$ and has more positive $\Delta^{33} \mathrm{~S}$ than when only SRP are included. This is reflected by the field labeled SRP/SDP system (Fig. 1). These model results form the basis for the use of the isotopic composition of proxies for seawater sulfate to distinguish the role of microbial sulfur disproportionation within the global sulfur cycle.

We measured the sulfur isotopic composition of 49 Proterozoic to Cambrian sulfate samples from either carbonate-associated sulfate (CAS) (35 in total) or sulfate minerals (14 in total) (table S1). In Fig. 2, the $\Delta^{33} \mathrm{~S}$ and $\delta^{34} \mathrm{~S}$ values of these samples are plotted relative to fields for the modeled SRP system and the modeled SRP/SDP system (27). Our model interpretation of these measurements assumes that they represent a well-mixed, homogeneous seawater sulfate reservoir whose composition is set by global processes. The majority of the Neoproterozoic/Cambrian data in Fig. $2 \mathrm{~A}$ occupies the modeled SRP/SDP field. This $\Delta^{33} \mathrm{~S}$ and $\delta^{34} \mathrm{~S}$ evidence for active microbial sulfur disproportionation is consistent with phylogenetic studies and previous interpretations of the $\delta^{34} \mathrm{~S}$ record (1). Our approach, however, also yields evidence for an active SRP/SDP system in the Mesoproterozoic (Fig. 2B), leading to the suggestion that microbial sulfur disproportionation was not initiated in the Neoproterozoic but instead operated for at least part of the Mesoproterozoic (17).

The isotopic composition of seawater sulfate from the Mesoproterozoic Society Cliffs Formation $[\sim 1200$ million years (My) old] and the Dismal Lakes Group ( $\sim 1300$ My old $)$ shows evidence for active microbial sulfur dispro-

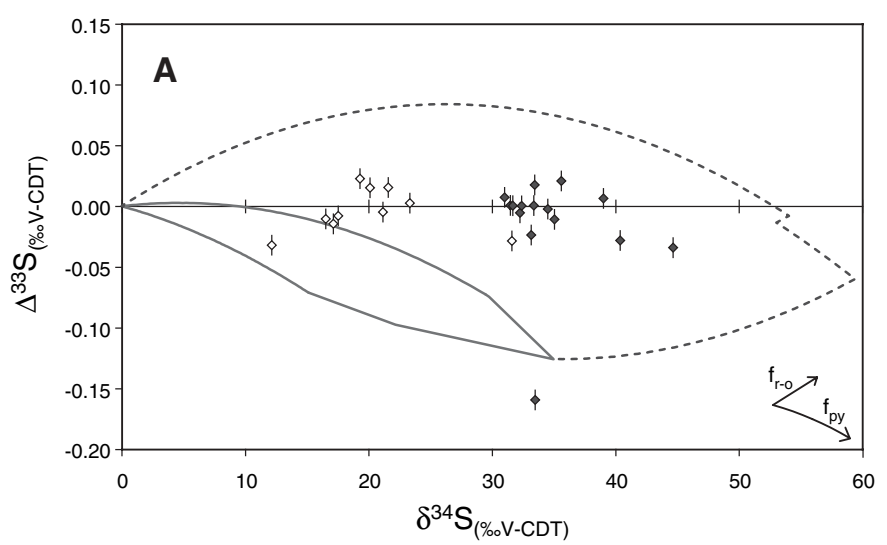

Fig. 2. Measured $\Delta^{33} \mathrm{~S}$ versus $\delta^{34} \mathrm{~S}$ values for Proterozoic-Cambrian seawater sulfate proxies combined with model predictions (Fig. 1). Measurement uncertainties are $0.008 \%$ in $\Delta^{33} \mathrm{~S}$ (shown in figure) and $0.12 \%$ in $\delta^{34} \mathrm{~S}$ (smaller than symbol size) for all data reported. (A) Neoproterozoic-Cambrian data (1000 to $500 \mathrm{Ma}$ ) divided into older (1000

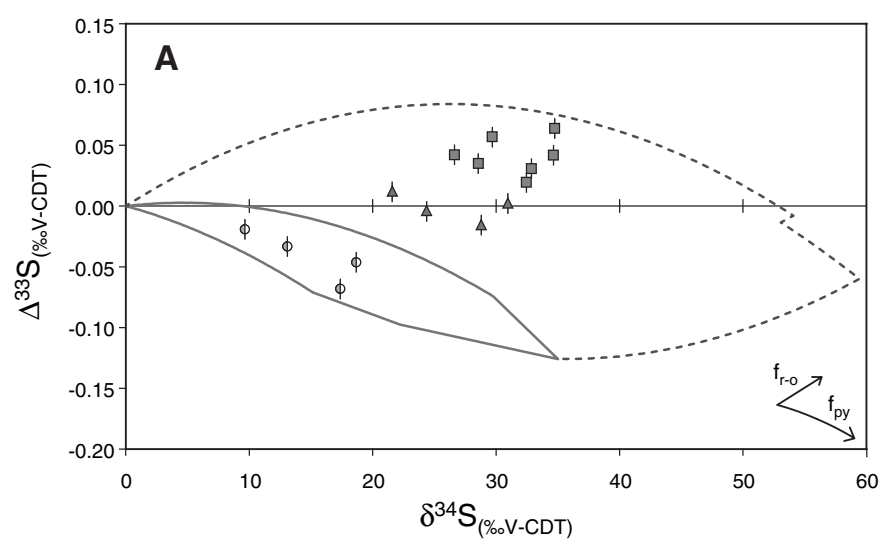

Fig. 3. Measured $\Delta^{33} S$ versus $\delta^{34} S$ values for seawater sulfate proxies from Mesoproterozoic basins and model predictions (Fig. 1). (A) The $\sim 1200$-My-old Society Cliffs Formation (solid squares) and the 1300-My-old Dismal Lakes Group (solid triangles) require active sulfur disproportionation at the time of their deposition. Samples from the $\sim 1450-M y$-old Helena Formation (circles) fit within the bounds of a strict SRP system and do not require the presence of SDP. (B)

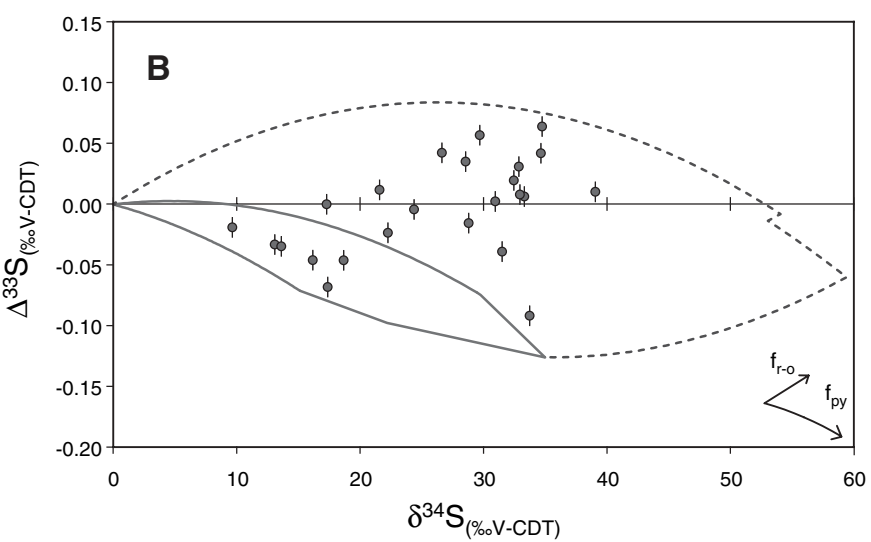

to $750 \mathrm{Ma}$; open diamonds) and younger (571 to $500 \mathrm{Ma}$; solid diamonds) groups. Variation between the two groups likely reflects differences in $f_{\mathrm{py}}$ in a system with both SRP and SDP. (B) Paleo- to Mesoproterozoic data (2000 to $1000 \mathrm{Ma}$; solid circles). The Paleo- and Mesoproterozoic data extend across a range that is defined by the SRP system and the SRP/SDP system.

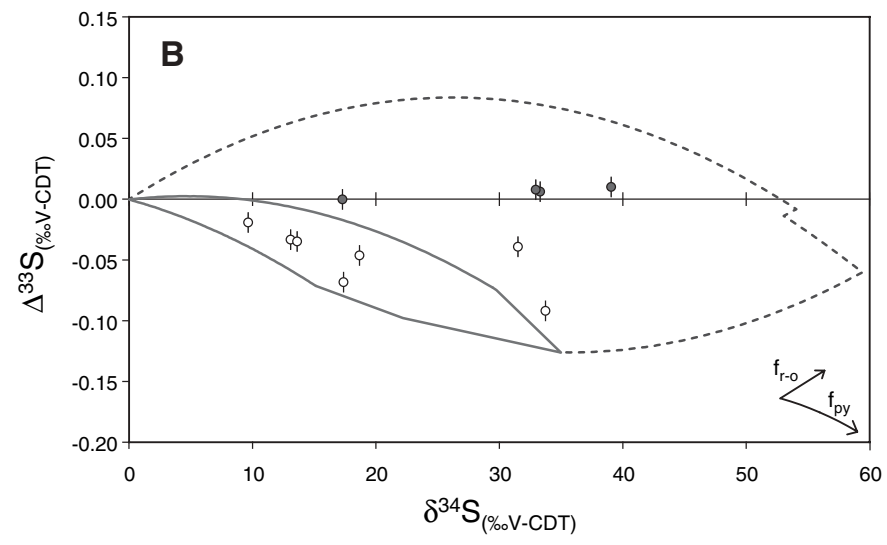

Measured $\Delta^{33} S$ versus $\delta^{34} S$ values from pre-1300-My-old basins (circles) plot, for the most part, in the SRP system field. Solid circles for the $\sim 1660$-My-old McNamara Group span almost the complete range of values observed for Proterozoic sulfate and exhibit a linear correlation with $\Delta^{33} S$ measurements. These isotopic systematics are consistent with the exclusive operation of SRP on a limited sulfate pool. 
portionation (Fig. 3A). The Society Cliffs data contain a strong SDP signature, and the relation between this data and the model indicates extensive sulfur processing through disproportionation reactions. The $\Delta^{33} S-\delta^{34} S$ data for Dismal Lakes samples also contain an SDP signature and are consistent with lower proportions of sulfide reoxidation and pyrite burial. In contrast, the isotopic compositions of CAS in the 1450-My-old Helena Formation are consistent with a strict SRP system (Fig. 3A) and do not require the influence of SDP. Our data indicate that SDP became progressively more important in the global sulfur cycle over the $\sim 250$-million-year time interval from 1450 to 1200 My old. Although these conclusions should be confirmed with additional data from other Mesoproterozoic basins, most pre-1300My-old samples in the current data set exhibit $\Delta^{33} S-\delta^{34} S$ values that unambiguously reflect an SRP-only system (table S1 and Fig. 3B).

Thus far, samples from only one pre1300-My-old sedimentary basin (McNamara Group, $\sim 1660$ My old) (Fig. 3B) appear to be inconsistent with the conclusions drawn above. These data, however, display some unusual isotopic characteristics. The $\delta^{34} \mathrm{~S}$ values of these samples span a wide range ( $\sim 17$ to $39 \%$ ), covering a substantial portion of the entire data set $(\sim 9$ to $44 \%$ ). In addition, McNamara $\Delta^{33} \mathrm{~S}$ values vary in a near-linear fashion with $\delta^{34} \mathrm{~S}$ values. Both of these characteristics are indicative of Rayleigh fractionation, and we can reproduce the McNamara data with such a model involving only SRP (21). Although we cannot rule out the possibility that the McNamara samples retain isotopic evidence of the effects of disproportionation, we hypothesize that this formation records a sulfur cycle dominated by SRP operating on a limited sulfate pool. This hypothesis is consistent with recent discussions of low sulfate concentrations during the deposition of the McNamara Basin sediments $(11,28)$, and it is testable by sulfur isotope analysis of sedimentary sulfides that formed contemporaneously with carbonates of the McNamara Group (29).

Taken together, our results bracket the appearance of a globally significant disproportionation pathway between 1450 and $1300 \mathrm{Ma}$. This predates prior estimates by several hundred million years (1) and exposes an inherent limitation of the use of $\delta^{34} \mathrm{~S}$ to explore biogeochemical aspects of the sulfur cycle. Positive $\delta^{34} \mathrm{~S}$ evidence for SDP requires that the fractionations expressed in the isotope record must exceed the extreme fractionations observed for SRP (1). By contrast, ${ }^{33} \mathrm{~S}$ traces the contribution of microbial disproportionation at smaller ${ }^{34} \mathrm{~S} /{ }^{32} \mathrm{~S}$ fractionations that would seem to be completely consistent with sulfate reduction from $\delta^{34} \mathrm{~S}$ alone.

Although the new ${ }^{33} \mathrm{~S}$ measurements suggest a major change in the microbial regimes that controlled the isotopic composition of Proterozoic seawater sulfate, the environmental impetus for this change is less clear. The intermediate sulfur compounds required for SDP are generated by chemical oxidation of sulfide by $\mathrm{O}_{2}$ and metal oxides $(1,14)$, by photosynthetic sulfide oxidizers (1), and by $\mathrm{O}_{2}$ - or nitraterespiring anaerobic nonphotosynthetic sulfide oxidizers $(1,14)$. On modern Earth, the compounds produced by these processes occur in a variety of chemical transition zones, such as at oxic-anoxic interfaces in marine sediments and stratified water columns and within the layers of microbial mat communities (15). We suggest that sulfur disproportionation dominantly occupied surface ocean and/or shelf environments where local oxidative processes were responsible for the production of sulfur intermediates. Other indicators of an oxidative surface environment, such as $\delta^{13} \mathrm{C}$ variations $(11,30)$, evolutionary arguments $(1,31)$, and sulfate concentration estimates $(11,28)$, are temporally consistent with a Mesoproterozoic onset of disproportionation. A high-resolution ${ }^{33} \mathrm{~S}$ record from the critical interval between 1450 and $1300 \mathrm{Ma}$ may capture this onset in action, revealing whether the rise of SDP lagged or accompanied the progressive oxygenation of Earth's surface.

\section{References and Notes}

1. D. E. Canfield, A. Teske, Nature 382, 127 (1996).

2. D. E. Canfield, Nature 396, 450 (1998).

3. Y. A. Shen, R. Buick, D. E. Canfield, Nature 410, 77 (2001).

4. H. G. Thode, J. Monster, H. B. Dunford, Geochim. Cosmochim. Acta 25, 159 (1961).

5. W. T. Holser, M. Schidlowski, F. T. Mackenzie, J. B. Maynard, in Chemical Cycles in the Evolution of Earth, C. B. Gregor et al., Eds. (Wiley, New York, 1988), pp. 105-173.

6. D. E. Canfield, in Stable Isotope Geochemistry, vol. 43 of Reviews in Mineralogy and Geochemistry, J. W. Valley, D. Cole, Eds. (Mineralogical Society of America, Washington, DC, 2001), pp. 607-636.

7. E. C. Perry Jr., J. Monster, T. Reimer, Science 171 , 1015 (1971)

8. K. Hattori, F. A. Campbell, H. R. Krouse, Nature 302, 323 (1983).

9. H. Ohmoto, T. Kakegawa, D. R. Lowe, Science 262, 555 (1993).

10. K. S. Habicht, M. Gade, B. Thamdrup, P. Berg, D. E. Canfield, Science 298, 2372 (2002).

11. L. C. Kah, T. W. Lyons, T. D. Frank, Nature 431, 834 (2004).

12. F. Bak, N. Pfenning, Arch. Microbiol. 147, 184 (1987).
13. D. E. Canfield, B. Thamdrup, S. Fleischer, Limnol. Ocean. 43, 253 (1998).

14. B. Thamdrup, K. Finster, J. W. Hansen, F. Bak, Appl. Environ. Microbiol. 59, 101 (1993).

15. H. Troelsen, B. B. Jorgensen, Estuarine Coastal Shelf Sci. 15, 255 (1982).

16. M. T. Hurtgen, M. A. Arthur, N. S. Suits, A. J. Kaufman, Earth Planet. Sci. Lett. 203, 413 (2002).

17. M. T. Hurtgen, M. A. Arthur, G. P. Halverson, Geology 33, 41 (2005)

18. J. Farquhar et al., Geobiology 1, 27 (2003).

19. D. T. Johnston, J. Farquhar, B. A. Wing, A. J. Kaufman, D. E. Canfield, K. S. Habicht, Am. J. Sci. 305, 645 (2005).

20. The detailed cellular mechanisms responsible for these differences are unknown. However, the observed isotope effects likely reflect mass-balance and enzymatic controls on isotopic fractionation in metabolic networks $(18,19)$.

21. Materials and methods, along with model sensitivity calculations and the derivation/results of the Rayleigh model are available on Science Online.

22. J. Farquhar, H. Bao, M. Thiemens, Science 289, 756 (2000).

23. J. R. Hulston, H. G. Thode, J. Geophys. Res. 70, 3475 (1965).

24. R. M. Garrels, A. Lerman, Proc. Natl. Acad. Sci. U.S.A. 78, 4652 (1981).

25. L. R. Kump, R. M. Garrels, Am. J. Sci. 286, 337 (1986).

26. R. A. Berner, Am. J. Sci. 287, 177 (1987).

27. Although the results in Fig. 1 have their basis in the assumption that the sulfate entering the model is unfractionated relative to bulk Earth estimates, the relative positions of the SRP and SRP/SDP fields are not affected by variations in the isotopic composition of the sulfate entering the model. Specific inferences about the exact values of $f_{\mathrm{py}}$ and $f_{\mathrm{r}-\mathrm{o}}$ that are implied by $\Delta^{33} S$ and $\delta^{34} S$ measurements of seawater sulfate proxies depend on the assumed isotopic composition of the sulfate entering the model. Because of this, we focus our interpretation of the new measurements on their general placement within the SRP and SRP/SDP fields. Our conclusions are valid with reasonable isotopic variations of the incoming sulfate $\left[\delta^{34} S \sim 0 \pm 5 \%\right.$ (5); $\Delta^{33} S \sim$ $0 \pm 0.03 \%$ ].

28. A. M. Gellatly, T. W. Lyons, Geochim. Cosmochim. Acta 69, 3813 (2005).

29. The $\delta^{34} S$ values of sulfide formed in a steady-state SRP/SDP system will be negative, whereas the $\Delta^{33} S$ values will be $<0.1 \%$ (fig. S3A). The $\delta^{34} \mathrm{~S}$ values of sulfide formed in a SRP system operating on a limited sulfate pool will be much less negative (or even positive), and the $\Delta^{33} S$ values will be $>0.1 \%$ (fig. S3B).

30. T. D. Frank, L. C. Kah, T. W. Lyons, Geol. Mag. 140, 397 (2003)

31. A. H. Knoll, Proc. Natl. Acad. Sci. U.S.A. 91, 6743 (1994).

32. We acknowledge support from NSF [EAR 0348382 (J.F.), EAR 9725538 (T.W.L. and L.C.K.), and EAR 0418005 (A.J.K.)], NASA (NAG512350 and NNG05GQ96G), the NASA Astrobiology Institute (D.T.J., B.A.W., and J.F.), and Danish National Research Foundation (Denmark's Grundforskningsfond, D.E.C.) for this research. We also thank J. W. Schopf for the contribution of samples labeled as PPRG (Precambrian Paleobiology Research Group).

\section{Supporting Online Material}

www.sciencemag.org/cgi/content/full/310/5753/1477/ DC1

Materials and Methods

SOM Text

Figs. $\mathrm{S} 1$ to $\mathrm{S} 3$

Tables S1 and S2

22 July 2005; accepted 1 November 2005 10.1126/science. 1117824 